Research Square
Preprints are preliminary reports that have not undergone peer review.

They should not be considered conclusive, used to inform clinical practice, or referenced by the media as validated information.

\title{
Viability of Natural Populations of Hypancistrus zebra (Siluriformes, Loricariidae), Xingu, Brazil
}

Liriann Chrisley Nascimento Da Silva ( $\sim$ lirianncns@gmail.com )

Federal University of Para

Leandro Melo de Sousa

Federal University of Para

Paulo De Marco Jr.

Universidade Federal de Goiás

Thiago Bernardi Vieira

Federal University of Para

\section{Research Article}

Keywords: Individual Based Modeling, Overfishing, Habitat loss, Ornamental fish, Volta Grande do Xingu

Posted Date: January 31st, 2022

DOI: https://doi.org/10.21203/rs.3.rs-1233118/v1

License: () (1) This work is licensed under a Creative Commons Attribution 4.0 International License. Read Full License 


\section{Abstract}

Hypancistrus zebra is an endemic fish species from the Middle Xingu River and recently included in the Critically Endangered (CR) category in the Red Book List of Endangered Brazilian Fauna that follows IUCN criteria. Given these impacts and the lack of information about the species, it is difficult to assume the viability of natural populations. Thus, this work aims to evaluate the effect of the variation of intrinsic parameters on the population viability of $H$. zebra. For this, an Individual Based Model (MBI) was created of the type Agent Based Modeling (MBA). To create the model, we considered "individuals" as an entity and the following variables of interest: longevity, age of sexual maturity, annual reproduction number, instant birth rate (b0), instant mortality rate (d0), interference of each individual in population growth (b1), interference of each individual in population mortality (d1), time (t), radius, richness (S), tolerance (tol) and population size $(\mathrm{N})$. The model showed that natural populations today, even not taking human impacts in account, are at the limit of viability. However, any factor that causes a reduction in resource availability, even if not evident, can lead to a steep population decline, affecting the viability of the populations.

\section{Introduction}

The construction of Hydroelectric Power Plants (HPP) has become one of the main threats to the maintenance of the global ichthyofauna ${ }^{1-3}$. The dam causes the blocking of migratory fish activities (e.g. reproductive migration of Salmo salar), physical changes (e.g. change from lotic to lentic environment and retention in sediment transport), chemical changes (e.g. physicochemical water characteristics) and affects community (e.g. causes the process of biotic homogenization, contaminates individuals with methyl mercury, favors the increase of generalist species and the disappearance of specialist species) ${ }^{4-13}$. These impacts change the dynamics of aquatic communities and populations s2,14,15. $^{2}$.

After damming, lotic fish communities are replaced by lentic species, since the dam reduces the water flow, transforming the natural water regime into a characteristic environment of lakes and reservoirs $5,7,16,17$. Physical and chemical water change, such as flow alteration and irregular seasonal variation downstream of the reservoir ${ }^{18,19}$, causes the loss of flooded area and reduction of areas for reproduction and foraging ${ }^{12,19,20}$. The reduction of areas destined for foraging and reproduction is also observed upstream of the impoundment and causes a reduction in fish populations ${ }^{8,12}$, however, the loss of upstream areas is linked to the drowning of environments, while downstream is linked to the period of permanent drought, created by the dam. Additionally, we observed a process of discontinuity in the rivers, which hinders the access of migratory fish to the headwaters to reproduce and later return, in turn, the fish from the eggs hatched above the dam are prevented from going downstream to grow ${ }^{21-23}$. These effects lead to the loss of fish diversity, therefore, reducing the abundance of populations can be the representation of a feeding strategy ${ }^{18}$ and result in changes in the fish assemblage ${ }^{5}$.

We are currently seeing an advance in studies in temporal and spatial scales in an attempt to mitigate the damage caused by the construction of dams ${ }^{2,3,14}$, 24-30. Despite these advances, the lack of information about some groups of species and environments is still scarce, especially in the neotropical region $22,23,26,27$. This lack of knowledge associated with the expansion of these projects increases the risk of local extinctions of endemic populations and species $^{28}$. Ecological modeling can be an effective method for studies with little data available and enables results in shorter time intervals ${ }^{29}$. In addition, Individual-Based Models (IBM) has increasingly stood out for being a more realistic ecological analysis when compared to classical models ${ }^{30}$.

IBM is mainly characterized by using individuals as a basic unit that interact and differ from each other, making the population no longer represent a continuous variable and become a set of discrete entities ${ }^{30,31}$. Despite working at individual-level, the simulations can achieve results at the level of population, community and even ecosystem organization ${ }^{30,32}$. Thus, the Population Viability Analysis (PVA) through extinction risk estimation performed by IBM provides a good way to access the status species of interest ${ }^{30,33-36}$.

Tropical rivers are representatives of the greatest diversity of freshwater fish in the world, only in the neotropical region there are 8000 described species ${ }^{2,37}$. This region has been undergoing an accelerated process of implementation of hydroelectric plants, from small to large dams ${ }^{2}$. In the Brazilian Amazon alone, 416 projects have already been implemented and 334 are being planned ${ }^{3,14}$. This region has a high potential for hydroelectric expansion, as it has large stretches of rapids and waterfalls $3,38,39$, and is home to about $16 \%$ ( 2411 described species) of fish diversity. Due to the characteristics of the environments (presence of rapids and waterfalls) the places where these projects are implemented have fish fauna with great diversity of species, morphological and functional ${ }^{2,40}$. An example of this are the hydroelectric projects on the Madeira and Xingu rivers ${ }^{2,37}$. Located on the Xingu River, Belo Monte HPP may be the record holder in terms of loss of biodiversity, as it is located in a highly endemic place ${ }^{41}$. Belo Monte was built in the middle Xingu River region, in a stretch known as Volta Grande do Xingu, home to populations of rare and endemic species with lithophytic and current habits ${ }^{42,43}$.

Among these populations, those of Hypancistrus zebra Isbrucker \& Nijssen, 1991, stand out, since the project covers the entire area of occurrence of the species. Currently, this species is included in the category of Critically Endangered according to the A3c criterion, which deals with a reduction $\geq 80 \%$ of the past, present or projected population, based on habitat quality and/or reduction of the occupied area (AOO) and extent of occurrence (EOO) ${ }^{44}$. Hypancistrus zebra is a species of fish in the subfamily Hypostominae (Loricaridae, Siluriforme) known for having a black and white oblique stripe pattern on the body and fins, and a snout with an "E"-shaped "striped" pattern ${ }^{45-47}$. These characteristics allow it to be highly valued in the ornamental fish market, and the high value of acquiring the specimen has generated great demand in the clandestine market ${ }^{56,48}$. However, the impact caused by the Belo Monte HPP is the main concern regarding the viability of its populations ${ }^{44}$. Furthermore, there are no data, or even predictions, about the current situation of natural populations of $H$. zebra.

Therefore, we seek to understand how the variation in the intrinsic parameters of the species $\mathrm{H}$. zebra can affect its population viability. Additionally, we intend to answer the following questions: (I) What are the combinations between the values of birth and death rates necessary to keep the population viable? (II) What are the combinations between the level of influence of habitat specialization and intraspecific competition in the persistence of this species? (III) Based on the generated scenarios, what is the viability condition of natural populations? 


\section{Results}

The algorithm that describes the effect of birth and mortality rates on the population viability of $\mathrm{H}$. zebra (MetaZebra 01 ) presented 137 (31\%) scenarios with $100 \%$ persistence of the populations (Table 1). The remaining scenarios, 304 (69\%), had some chance of extinction, ranging from 0.020 to 1,000 , with 201 $(45 \%)$ of the scenarios having a probability greater than $50 \%$ of extinction and $162(36.7 \%)$ of the scenarios had $100 \%$ chances of extinction (Table 1$)$. Based on our results, the combinations between the values of birth and death rates necessary to keep the population viable must have a birth rate greater than 0.55 and a mortality rate lower than 0.25 . Otherwise, the population starts to decline, however it does not inhibit the chances of the population re-establishing itself. However, if a $b$ is less than 0.55 and $d$ greater than 0.6 , the population goes into extinction.

Table 1

Values of population survival probability in different combinations in the birth rate (b) and in the mortality rate (d) estimated by the model. Values closer to gre persistence of the population, values in yellow and next to the red are scenarios between mid to low chances of persistence. While values in red represent $100 \%$

\begin{tabular}{|c|c|c|c|c|c|c|c|c|c|c|c|c|c|c|c|c|c|}
\hline \multirow{21}{*}{$\begin{array}{l}\text { Birth } \\
\text { rade } \\
\text { (b) }\end{array}$} & 1 & 1,000 & 1,000 & 1,000 & 1,000 & 1,000 & 1,000 & 1,000 & 1,000 & 1,000 & 1,000 & 1,000 & 1,000 & 1,000 & 0,862 & 0,687 & 0,482 \\
\hline & 0,95 & 1,000 & 1,000 & 1,000 & 1,000 & 1,000 & 1,000 & 1,000 & 1,000 & 1,000 & 1,000 & 1,000 & 0,799 & 0,915 & 0,905 & 0,750 & 0,535 \\
\hline & 0,9 & 1,000 & 1,000 & 1,000 & 1,000 & 1,000 & 1,000 & 1,000 & 1,000 & 1,000 & 1,000 & 1,000 & 0,779 & 0,905 & 0,817 & 0,723 & 0,468 \\
\hline & 0,85 & 1,000 & 1,000 & 1,000 & 1,000 & 1,000 & 1,000 & 1,000 & 1,000 & 1,000 & 1,000 & 1,000 & 0,766 & 0,765 & 0,795 & 0,767 & 0,288 \\
\hline & 0,8 & 1,000 & 1,000 & 1,000 & 1,000 & 1,000 & 1,000 & 1,000 & 1,000 & 1,000 & 1,000 & 1,000 & 0,559 & 0,739 & 0,783 & 0,738 & 0,297 \\
\hline & 0,75 & 1,000 & 1,000 & 1,000 & 1,000 & 1,000 & 1,000 & 1,000 & 1,000 & 1,000 & 1,000 & 1,000 & 0,537 & 0,647 & 0,437 & 0,261 & 0,160 \\
\hline & 0,7 & 1,000 & 1,000 & 1,000 & 1,000 & 1,000 & 1,000 & 1,000 & 1,000 & 0,900 & 1,000 & 1,000 & 0,499 & 0,323 & 0,292 & 0,314 & 0,000 \\
\hline & 0,65 & 1,000 & 1,000 & 1,000 & 1,000 & 1,000 & 1,000 & 1,000 & 1,000 & 1,000 & 0,990 & 1,000 & 0,350 & 0,252 & 0,272 & 0,000 & 0,000 \\
\hline & 0,6 & 1,000 & 1,000 & 1,000 & 1,000 & 1,000 & 1,000 & 1,000 & 1,000 & 1,000 & 1,000 & 1,000 & 0,350 & 0,110 & 0,000 & 0,000 & 0,000 \\
\hline & 0,55 & 1,000 & 1,000 & 1,000 & 1,000 & 0,896 & 0,758 & 0,755 & 0,517 & 0,485 & 0,366 & 0,276 & 0,320 & 0,000 & 0,000 & 0,000 & 0,000 \\
\hline & 0,5 & 1,000 & 1,000 & 1,000 & 1,000 & 0,887 & 0,633 & 0,416 & 0,363 & 0,330 & 0,325 & 0,311 & 0,262 & 0,000 & 0,000 & 0,000 & 0,000 \\
\hline & 0,45 & 1,000 & 1,000 & 1,000 & 1,000 & 1,000 & 1,000 & 1,000 & 0,864 & 0,463 & 0,404 & 0,261 & 0,170 & 0,000 & 0,000 & 0,000 & 0,000 \\
\hline & 0,4 & 1,000 & 1,000 & 0,980 & 0,990 & 1,000 & 0,610 & 0,488 & 0,454 & 0,362 & 0,335 & 0,098 & 0,125 & 0,000 & 0,000 & 0,000 & 0,000 \\
\hline & 0,35 & 1,000 & 1,000 & 1,000 & 0,950 & 1,000 & 0,970 & 0,877 & 0,748 & 0,685 & 0,379 & 0,132 & 0,043 & 0,000 & 0,000 & 0,000 & 0,000 \\
\hline & 0,3 & 1,000 & 1,000 & 0,960 & 1,000 & 0,958 & 0,795 & 0,790 & 0,504 & 0,493 & 0,266 & 0,076 & 0,000 & 0,000 & 0,000 & 0,000 & 0,000 \\
\hline & 0,25 & 1,000 & 1,000 & 1,000 & 0,890 & 0,744 & 0,573 & 0,354 & 0,351 & 0,182 & 0,171 & 0,076 & 0,000 & 0,000 & 0,000 & 0,000 & 0,000 \\
\hline & 0,2 & 1,000 & 1,000 & 1,000 & 1,000 & 1,000 & 0,964 & 0,781 & 0,768 & 0,471 & 0,139 & 0,043 & 0,000 & 0,000 & 0,000 & 0,000 & 0,000 \\
\hline & 0,15 & 1,000 & 1,000 & 0,949 & 0,864 & 0,852 & 0,578 & 0,532 & 0,463 & 0,299 & 0,209 & 0,201 & 0,105 & 0,000 & 0,100 & 0,000 & 0,000 \\
\hline & 0,1 & 1,000 & 1,000 & 0,907 & 0,902 & 0,698 & 0,575 & 0,261 & 0,221 & 0,211 & 0,170 & 0,094 & 0,000 & 0,063 & 0,000 & 0,000 & 0,000 \\
\hline & 0,05 & 1,000 & 0,964 & 0,958 & 0,846 & 0,793 & 0,739 & 0,697 & 0,498 & 0,424 & 0,417 & 0,306 & 0,000 & 0,000 & 0,000 & 0,000 & 0,000 \\
\hline & 0 & 0,000 & 0,000 & 0,000 & 0,000 & 0,000 & 0,000 & 0,000 & 0,000 & 0,000 & 0,000 & 0,000 & 0,000 & 0,000 & 0,000 & 0,000 & 0,000 \\
\hline & & 0 & 0,05 & 0,1 & 0,15 & 0,2 & 0,25 & 0,3 & 0,35 & 0,4 & 0,45 & 0,5 & 0,55 & 0,6 & 0,65 & 0,7 & 0,75 \\
\hline
\end{tabular}

As for the algorithm used to describe the influence of the level of habitat specialization and intraspecific competition on the species' persistence (MetaZebra 02), we had 219 (49.6\%) scenarios with $100 \%$ persistence (Table 2). There were 345 (78.2\%) scenarios with a greater than $50 \%$ of persistence. Our results showed that the combinations between the values of the rates of tolerance level and radius of competition necessary to maintain the persistence of the population owe the level of tolerance with a rate greater than 0.5 and a radius of competition with a rate less than 0.4 . No scenario presented a $100 \%$ chance of extinction of the population (Table 2). As for the level of influence of habitat specialization and competition, the results showed that tolerance has a greater influence on population persistence than the effect generated by intraspecific competition. The competition starts to act more conspicuously on the population from radius greater than 0.4 . The tolerance level is more likely to keep populations viable with tolerance rates higher than 0.5 , below these rates the population starts to influence population decline. 
Table 2

Values of probability of population persistence in different combinations in the tolerance rate and in the radius of intraspecific competition rate estimated by $t$ with greater chances of persistence of the population, values in yellow and close to red are scenarios between mid to low chances of persistence. While valu

\begin{tabular}{|c|c|c|c|c|c|c|c|c|c|c|c|c|c|c|c|c|c|}
\hline \multirow{21}{*}{$\begin{array}{l}\text { Tolerance } \\
\text { level (tx) }\end{array}$} & 1 & 1,000 & 1,000 & 1,000 & 1,000 & 1,000 & 1,000 & 1,000 & 1,000 & 1,000 & 1,000 & 1,000 & 1,000 & 1,000 & 1,000 & 1,000 & 1 \\
\hline & 0,95 & 1,000 & 1,000 & 1,000 & 1,000 & 1,000 & 1,000 & 1,000 & 1,000 & 1,000 & 1,000 & 1,000 & 1,000 & 1,000 & 1,000 & 1,000 & 0 \\
\hline & 0,9 & 1,000 & 1,000 & 1,000 & 1,000 & 1,000 & 1,000 & 1,000 & 1,000 & 1,000 & 1,000 & 1,000 & 1,000 & 0,927 & 1,000 & 1,000 & 1 \\
\hline & 0,85 & 1,000 & 1,000 & 1,000 & 1,000 & 1,000 & 1,000 & 1,000 & 1,000 & 1,000 & 1,000 & 1,000 & 1,000 & 1,000 & 1,000 & 1,000 & 0 \\
\hline & 0,8 & 1,000 & 1,000 & 1,000 & 1,000 & 1,000 & 1,000 & 1,000 & 1,000 & 1,000 & 1,000 & 1,000 & 0,905 & 1,000 & 1,000 & 1,000 & 1 \\
\hline & 0,75 & 1,000 & 1,000 & 1,000 & 1,000 & 1,000 & 1,000 & 1,000 & 1,000 & 1,000 & 1,000 & 1,000 & 1,000 & 1,000 & 1,000 & 0,688 & 0 \\
\hline & 0,7 & 1,000 & 1,000 & 1,000 & 1,000 & 1,000 & 1,000 & 1,000 & 1,000 & 1,000 & 1,000 & 1,000 & 1,000 & 0,908 & 0,865 & 1,000 & 0 \\
\hline & 0,65 & 1,000 & 1,000 & 1,000 & 1,000 & 1,000 & 1,000 & 1,000 & 1,000 & 1,000 & 1,000 & 1,000 & 1,000 & 0,973 & 0,933 & 0,902 & 0 \\
\hline & 0,6 & 1,000 & 1,000 & 1,000 & 1,000 & 1,000 & 1,000 & 1,000 & 1,000 & 1,000 & 1,000 & 1,000 & 0,522 & 0,950 & 0,901 & 0,843 & 0 \\
\hline & 0,55 & 1,000 & 1,000 & 1,000 & 1,000 & 1,000 & 1,000 & 1,000 & 1,000 & 1,000 & 1,000 & 0,578 & 1,000 & 0,900 & 0,879 & 0,825 & 0 \\
\hline & 0,5 & 1,000 & 1,000 & 1,000 & 1,000 & 1,000 & 0,731 & 0,799 & 1,000 & 1,000 & 0,547 & 0,733 & 0,950 & 0,867 & 0,757 & 0,737 & 0 \\
\hline & 0,45 & 1,000 & 1,000 & 1,000 & 1,000 & 1,000 & 1,000 & 1,000 & 1,000 & 0,914 & 1,000 & 1,000 & 0,842 & 0,836 & 0,747 & 0,698 & 0 \\
\hline & 0,4 & 1,000 & 1,000 & 1,000 & 1,000 & 1,000 & 1,000 & 1,000 & 1,000 & 0,699 & 0,588 & 1,000 & 0,807 & 0,780 & 0,694 & 0,679 & 0 \\
\hline & 0,35 & 1,000 & 1,000 & 1,000 & 1,000 & 1,000 & 1,000 & 1,000 & 1,000 & 0,966 & 1,000 & 1,000 & 0,748 & 0,554 & 0,538 & 0,517 & 0 \\
\hline & 0,3 & 1,000 & 1,000 & 1,000 & 1,000 & 1,000 & 0,938 & 1,000 & 1,000 & 1,000 & 1,000 & 1,000 & 0,731 & 0,485 & 0,474 & 0,430 & 0 \\
\hline & 0,25 & 1,000 & 1,000 & 1,000 & 1,000 & 0,969 & 1,000 & 0,950 & 0,504 & 1,000 & 0,995 & 0,712 & 0,684 & 0,472 & 0,405 & 0,394 & 0 \\
\hline & 0,2 & 1,000 & 1,000 & 1,000 & 1,000 & 1,000 & 1,000 & 1,000 & 1,000 & 0,954 & 0,673 & 0,633 & 0,607 & 0,465 & 0,379 & 0,347 & 0 \\
\hline & 0,15 & 1,000 & 1,000 & 1,000 & 1,000 & 1,000 & 1,000 & 1,000 & 1,000 & 0,893 & 0,582 & 0,540 & 0,516 & 0,464 & 0,339 & 0,285 & 0 \\
\hline & 0,1 & 1,000 & 1,000 & 1,000 & 0,980 & 1,000 & 0,994 & 0,302 & 1,000 & 0,882 & 0,561 & 0,477 & 0,357 & 0,266 & 0,261 & 0,217 & 0 \\
\hline & 0,05 & 1,000 & 1,000 & 1,000 & 1,000 & 1,000 & 0,759 & 1,000 & 0,748 & 0,564 & 0,358 & 0,357 & 0,294 & 0,237 & 0,150 & 0,146 & 0 \\
\hline & 0 & 0,980 & 0,938 & 0,837 & 0,746 & 0,616 & 0,396 & 0,328 & 0,326 & 0,319 & 0,270 & 0,227 & 0,196 & 0,113 & 0,098 & 0,087 & 0 \\
\hline & & 0 & 0,05 & 0,1 & 0,15 & 0,2 & 0,25 & 0,3 & 0,35 & 0,4 & 0,45 & 0,5 & 0,55 & 0,6 & 0,65 & 0,7 & 0 \\
\hline
\end{tabular}

Based on the scenarios generated by the MetaZebra 01 algorithm (Table 1 ) and considering the birth rate of 0.6 and the intrinsic mortality rate of 0.3 , natural populations have $100 \%$ probability of survival in nature. Considering this, the three natural populations would be viable, but sensitive changes in birth and mortality rates, as well as environmental changes.

\section{Discussion}

The 441 scenarios generated by the model showed that the relationship between the intrinsic birth rate above 0.6 with the intrinsic death rate below 0.5 allows populations to remain viable for a long time (Table 1). The model also showed that the number of scenarios with some extinction risk was higher (69\% of the scenarios) than the number of scenarios with a $100 \%$ chance of persistence. This may be an indication of the vulnerability of $H$. zebra populations to events that may change the demographic stochastic process.

Stochastic birth-and-death process is probably the simplest modeling approach to predicting extinction ${ }^{33,56}$. In simple models they are independent rates, but they can show high correlation through the years in real populations, since the temporal variation can provide years with high or low resource availability, affecting the reproduction and survival of individuals ${ }^{68}$. However, not always that the value of $\mathrm{R}$ is negative (the birth rate lower the death rate) is a guarantee of short-term population persistence, just as a high birth rate and low mortality do not guarantee long-term persistence of time ${ }^{68}$. The high number of scenarios expands the view of stochastic variation and can make it easier to predict the actual population fate. The persistence of a population depends on stochastic or variation ${ }^{69}$.

Generally, the persistence of a population is ensured by large, connected, suitable and close to each other habitats, high population reproductive rate and environmental conditions with variation in balanced carrying capacity ${ }^{70}$. Hypancistru zebra is an endemic species, restricted to about $170 \mathrm{~km}$ from the middle Xingu river ${ }^{44}$, possibly its populations are closed and currently the environmental conditions and available resources are not favorable due to the dam.

The variation in habitat quality in the landscape (spatial variation) also affects population persistence ${ }^{68}$, therefore, the feasibility presented by the model does not guarantee the real maintenance of $H$. zebra populations. Generally, stochastic events are of concern especially for viability of small populations ${ }^{33,71,72}$, as they present greater chances of extinction due to their demographic fluctuation, whether due to demographic stochasticity (internal mechanisms) or 
environmental stochasticity (external mechanisms) ${ }^{30,72,73}$. These events are linked to birth and death rates ${ }^{74}$. We consider that the three natural populations of $H$. zebra are represented by high population size, which could have a different result in viability if their populations go into decline, either by mortality or the removal of individuals with overfishing.

In the model, it was observed that tolerance has a greater influence on population persistence than the effect generated by intraspecific competition (competition radius; Table 2). Since the radius is less than 0.5 , the tolerance force is greater. However, in scenarios with a radius greater than 0.55 , competition starts to have a greater effect on populations, regardless of the high tolerance rate. Therefore, even in scenarios with a high tolerance rate, the probability of population extinction will be greater when the competition radius reaches high values in the rate. However, if both rates are low, it is possible that the population will be maintained. This indicates that intraspecific competition is an interaction that acts more visibly in the population from a radius greater than 0.4. On the other hand, the tolerance level is more likely to maintain viable populations with tolerance rates greater than 0.5 , below these rates the population starts to present a greater risk of extinction.

We did not include effects of anthropogenic actions in the study. We emphasize that models that address the variation between individuals is essential to develop and study population dynamics and associate it with different life history tactics ${ }^{75}$. The development of modeling with intrinsic parameters allows testing uncertain impacts on the life history, evaluating the demography of species ${ }^{76}$, in addition to making it possible to identify predominant parameters in the system when well delimited ${ }^{77}$.

Data from the life history or population growth rate are used for the functioning of the PVA, this information serve as parameters in the model projecting the population dynamics ${ }^{78}$. As these rates vary, they influence intrinsic processes (e.g. stochasticity, genetic drift, demographic, social structure) ${ }^{79}$, and given the fluctuation in population size and over time, random (stochastic) variation occurs. The greater the amount of information about the population, the more detailed is an $\mathrm{MBI}^{30}$, which benefits better results, but requires a more advanced computer system ${ }^{80,81}$. MBI is widely used to assess population dynamics through intrinsic rates 82 . Individual variation is the evolutionary basis existing in all populations and organisms and this individual heterogeneity occurs in practically all characteristics, including reproduction, physical conditioning and survival ${ }^{75,83-85}$.

Our results show a $100 \%$ probability of population viability for the three natural populations of $H$. zebra, given the combination of values of birth rate $(b=0.6)$ and intrinsic mortality $(\mathrm{d}=0.3)$. However, the models that generated the scenarios did not include fishing pressure and habitat change caused by the Belo Monte HPP, which covers the entire area of occurrence of the species ${ }^{56,57}$. Due to the fact that these impacts already exist in the area of occurrence of the species and already promote changes in conditions and resources, we can suggest that populations are threatened. Since a decrease in the birth rate or an increase in mortality would cause species to move from the area green ( $100 \%$ probability) for areas with a lower probability of viability.

The model that investigates the relationship between birth and mortality rates showed that birth rates below 0.55 and mortality rates above 0.25 can lead to extinctions. Our model populations showed little difference in these thresholds, 0.6 for birth and 0.3 for mortality, reinforcing the idea that natural populations nowadays would not be in conditions of $100 \%$ viability. Females of Hypancistrus zebra guarantees breed in plots and have low fertility 43 . This can demonstrate that the natural behavior of the species prioritizes spending more energy for individual maintenance than for reproduction, such as spending looking for mates and investing in offspring. In the absence of a good amount of available resources, individuals tend to choose to spend more energy with reproduction (increasing the birth rate of newborns and reducing adult individuals) or avoid the risk of mortality (lower mortality of mature individuals, but low rate of newborns) ${ }^{86}$, influencing a dynamic in population birth and mortality rates. Poor reproduction and high mortality (positive and/or negative covariance) also result in resource availability in the face of temporal variation.

Loricariidae show low tolerance in sections of reservoir formation ${ }^{59}$ and species with characteristics adaptable to fast-flowing water habitats are more vulnerable to dams ${ }^{2}$. In addition, the model showed that natural populations of $H$. zebra are viable, but it is possible to observe that it is an intrinsically sensitive species and may be vulnerable to human disturbances. So it is also with regard to the level of specialization of the habitat. In Table 2 , no scenario showed $100 \%$ extinction, however, it is possible to observe that tolerance has a greater influence on the intraspecific competition radius, demonstrating the high specialization of the species. Although these is not small populations, it is an endemic species, with high removal of specimens from nature for illegal sale ${ }^{48,49}$ and its habitat is practically all affected by the implementation of a hydroelectric plant ${ }^{44}$. In addition, paucity of data is likely a major limitation in assessing population viability ${ }^{87}$.

The reduction in the birth rate can be a process of response to increased mortality, fewer individuals to reproduce, or the removal of individuals from the population, either through migration or fishing, in the case of fish. Another worrying factor in population decline is overexploitation of the species. Such a decline had already been reported due to the consequent history of exploitation and habitat loss caused by mining activities ${ }^{88}$ and even after the fishing prohibition, their specimens are still being collected due to their high value and difficult inspection ${ }^{89}$. In this way, it will promote a reduction in the population's birth rate, but the change in habitat does not only affect recruitment. Considering the paucity of studies on the niche and reproductive biology of $H$. zebra, possibly it is a kind of $k$-strategist due to its low fertility that takes time to reach sexual maturity, takes care of parents, is sedentary and has a long life cycle ${ }^{55-}$ 57. Given the parameters that fed the algorithms, the tolerance level is greater than the concurrency radius effect.

Our study presents a theoretical ecological intrinsic modeling for predicting how the populations of $H$. zebra will behave with variation of the parameters, showing that a high rate of withdrawal of individuals or impacts caused by the alteration of the water flow in the natural environment can cause a reduction of population viability that will generate extinction of its populations. In addition, some authors claim that $H$. zebra is sensitive to changes in water quality ${ }^{88}$ and climate changes ${ }^{90}$. In addition to these factors, the species is considered endemic ${ }^{42,47}$ which corroborates that it is a more specialized niche species. Their narrow tolerance range indicates that their populations are below the median tolerance level in Table 2, which should not be a concern if the current ecological condition is to contribute to greater competition between individuals for resources. In natural conditions without human alterations and capture pressure, 
natural populations of $H$. zebra are viable in a delicate balance, however, according to the model, small disturbances can promote a decline in population growth, generating great probabilities of the species' extinction. Impacts such as the change in the hydrological cycle caused by the Belo Monte HPP dam, as well as the high rate of specimen withdrawal by illegal fishing, will synergistically cause irreversible damage to the population viability of this species.

\section{Material And Methods}

In this research, was used the IBM type Agent Based Modeling (ABM). The algorithms used (Supplementary Material I, II and III) were developed within the platform Matlab ${ }^{\circledR}$ version R2015a ${ }^{50}$. The model description is structured according to the protocol ODD (Overview, Design concepts, Details) updated suggested by Grimm et al. (2010).

Purpose

The purpose of the models is to assess the effect of varying intrinsic parameters on the population viability of an endemic fish species. Although endemism and species unity are not a limiting feature for replicating models. Thus, the developed algorithms indicate how (i) the ratio between the birth and mortality rates (Supplementary II - MetaZebra01) and (ii) the level of specialization and competition (Supplementary III - MetaZebra02) of the specimens affect population viability.

Entities and state variables

The model has only one entity, specimens. The specimens are representatives of a single species of fish distributed in three populations of different sizes. Each specimen was characterized by a set of specific parameters based on information from literature and breeders of the species. Basically, we used characteristics that influence population dynamics, including the following state variables: longevity, age of sexual maturity, annual reproduction number, instant birth rate (b0), instant mortality rate (d0), interference of each individual in population growth (b1), interference of each individual in population mortality (d1), time (t), radius, richness (S), tolerance (tol) and population size $(\mathrm{N})$. We consider the following assumptions for determining the values of our variables:

Longevity. Species of the same family (e.g. Ancistrus ssp.) can reach more than 15 years of age ${ }^{51-53}$. According to aquarists, longevity in captivity is at least 15 years for the species under study. However, probably in a natural environment, specimens have a shorter life span when compared to individuals in good health in captivity ${ }^{54}$. Therefore, in the model, we estimate that specimens can reach 12 years of life in nature.

Age of sexual maturity. According to breeders who produce the species in captivity, individuals reach sexual maturity at the age of three.

Annual reproduction rate. To determine b0, we need to know the number of individuals who enter the cohort each year by birth. Because the male copulates with more than one female ${ }^{55}$, we only consider females in the calculation. We used $50 \%$ of the specimens of each hypothetical population, since the parameter is more related to the fertility of females, as the number of individuals depends more on that sex, so the sex ratio considered was 1:1. Each female spawns an average of 14 eggs per spawn ${ }^{48,55}$. In captivity, multiple spawning are observed throughout the year. In a natural environment, reproduction can occur at any time of the year, but two reproductive peaks were observed annually ${ }^{56,57}$. We estimate that $95 \%$ of the females in each cohort are able to reproduce. Most females spawn twice a year, possibly larger females with better nutritional performance, are more apt for a greater number of annual reproduction ${ }^{58}$. We consider the following rates: $35 \%$ of females reproduce only once / year, $45 \%$ reproduce twice/ year and only $15 \%$ of females reproduce three times / year.

Mortality rate. Regarding mortality, we arbitrarily define that in a natural environment despite parental care, the mortality of individuals under one year of age (juvenile and egg) is high, around $50 \%$, due to predation and competition for hide. Additionally, adult females are assigned a $25 \%$ mortality rate, while adult males have $20 \%$. We consider that the behavior of the male to stay hidden and protecting it's crevice (Ramon, 2011; Gonçalves, 2011) provides less vulnerability to males and consequently a lower mortality rate than females in the population.

Intrinsic birth rate (b0). According to the assumptions of the hypothetical natural population size and annual reproduction rate, we obtained the result of b0= 0,6 . We used only the females of each population ( $50 \%$ of the individuals) and the rate value was obtained through a difference equation presented in more detail in section 2.6 (sub-models).

Intrinsic mortality rate (d0). Following the assumptions of the hypothetical natural population size and annual mortality rate it was estimated as d0= 0,3 . We used only the females of each population ( $50 \%$ of the individuals) and the rate value was obtained through a difference equation presented in more detail in section 2.6 (sub-models).

Interference of each individual in the growth (b1) and mortality (d1) of the population. We did not consider the effect of b1 (interference of each individual on population growth) and d1 (interference of each individual on population mortality) in the models.

Time ( $\mathrm{t})$. Time was measured in years in models with $\mathrm{t}=0$ as a starting point, ending in 1,000 years.

Radius. The radius rate varies from 0 to 1 , being 0 when there is no competition and 1 when everyone is competing with each other. There are no studies that say how competitive the species is. So, we determine an average value (0.5).

Richness (S). As the study deals with the population of just one species, we considered S $=1$.

Tolerance (tol). There is also no information on the species tolerance, therefore, we determined an average value (0.5). 
Initial population size (N). In both modules of model execution, we considered $\mathrm{n}$ the initial size of the population with 100,000 individuals.

Process overview and scheduling

The processes of the models promote the simulation of the dynamics of individuals within the population in an environment without anthropic effects and interspecific interaction (Figure 1; Supplementary I - PopZebra). The process begins with the entry of a cohort with an initial number of individuals ( $\mathrm{n}=$ $10.000)$ in the population. Gradually, individuals are assigned to the Optimal level range (OLR) randomly determined, or to the Maximum or Minimum tolerance level range (LRMaxMin) ranging from zero to one, according to the model. Specimens included in the OLR are aged, go through the update of age and later young individuals go through the process of sexual maturity until they reach the age of sexual maturity (adult individuals), the individuals enter the reproduction process, causing the origin of a new cohort by birth.

As for the individuals that enter FNMaxMin, they are destined to the competition processes for resources (territorialism and / or food). Randomly, some individuals are classified as survivors and enter the aging process and the consecutive ones mentioned above, while the rest are removed from the model by the mortality process. Individuals who reach the age of longevity are also removed by the model through the process of natural mortality (by age).

This dynamic is generated through the PopZebra program (supplementary material I). However, to meet our objectives, two metaprograms were developed. MetaZebra 01 (supplementary material II) for objective one and MetaZebra 02 (supplementary material III) for objective two. The values of the variables used in the algorithms (shown in Table 3) are based in knowledge gathered in specialized hobbyists' magazines, hobbyists and fishermen personal communications, as well as experiments carried out in captive breeding program in the laboratory. The MetaZebra 01 algorithm was built to create combinations of birth and mortality, thus varying b0 and do from zero to one in 0.05 intervals. Considering $\mathrm{H}$. zebra as r or k strategist (depending on the mortality rate). This procedure will build an interface of values where the x-axis will be the entire variation of the mortality rate while the $y$-axis will be the entire variation of the birth rate and the 441 cells ( 21 birth values multiplied by 21 mortality values) will represent all possible combinations between these two rates. Thus, indicating the effect of the ratio between birth and mortality rates on population viability.

Table 3

Condition variables used in the algorithms to generate the models. Randomized values were determined by "Minimum Value: Interval: Maximum value".

\begin{tabular}{|llll|}
\hline Variables & PopZebra & MetaZebra 01 & MetaZebra 02 \\
\hline Maturidade sexual (year) & 3 & - & - \\
\hline Longevidade (year) & 12 & - & - \\
\hline b0 & - & $0: 0.05: 1$ & 0.6 \\
\hline b1 & 0 & - & - \\
\hline d0 & - & - & 0.3 \\
\hline d1 & 0 & $0: 0.05: 1$ & - \\
\hline t (year) & 1,000 & - & - \\
\hline raio & - & 0.5 & $0: 0.05: 1$ \\
\hline tol & - & 0.5 & $0: 0.05: 1$ \\
\hline sp ou S & 1 & - & - \\
\hline n & 100,000 & - & - \\
\hline
\end{tabular}

As for the MetaZebra 02 algorithm, it was created to vary the tolerance and the radius of competition, thereafter the tol and the radius vary from zero to one in 0.05 intervals. Considering the species as generalist or specialist (depending on the tolerance rate) and little or very competitive (depending on the competition radius rate) in the face of changes. This procedure will generate an interface of values, where the $x$ axis will be the entire variation of the competition radius rate and the $y$ axis will be the entire variation of the tolerance rate and, the 441 cells ( 21 tolerance values multiplied by 21 radius values competition) will represent all possible combinations between these two rates. This way, it is possible to compare the effect of the species' level of specialization (tolerance) and relate it to the influence of intraspecific competition on the persistence of $H$. zebra. Each algorithm generated 441 combinations of values (scenarios) that represent the population's probability of survival over an interval of 1,000 years. This probability was calculated from five replicates of each combination.

\section{Design concepts}

Basic principles. Population dynamics are maintained with the constant influence of several factors. Growth is determined by the number of entities (individuals) that enter (birth and migration) and leave (mortality and emigration) the population ${ }^{59}$. The population grows exponentially until it is controlled by the amount of resources available in the environment, called support capacity ${ }^{60}$. In addition, ecological factors within the habitat will influence the interaction between individuals (intraspecific interaction) and with the environment (Law of Tolerance), which depending on the level of specialization of the species will determine the growth and survival of this set of organisms ${ }^{61-63}$. We assumed, in the model under study, the population as being a closed one (entry of individuals by birth and exit by mortality), since it is an endemic species with no migratory characteristics, restricted to about $170 \mathrm{~km}$ of the river section.

Emergency. Population dynamics included an emerging result of behavior and interactions between individuals and their habitat. 
Interaction. Only internal interactions are recorded in the process. Intraspecific competition is about organisms of the same species that start competing for resources when demand is greater than what the environment can offer, causing a reduction in population growth due to mortality ${ }^{64,65}$. Another interaction that will influence the survival of individuals is the level of specificity in terms of habitat (general and specialist species). Species with a more generalized niche tend to occupy large geographical areas and are vulnerable to factors that reach large scales, while specialist species have a restricted niche, occupying small geographical areas, their populations are small and more vulnerable to extinction $63,66,67$, usually endemic and rare species are specialists.

Iniciation

Initially, the condition variables b0, b1, d0, d1, radius, time, n, S and tol generate the behavior curve of the population of the single species under study, executed through the IND function, creating the intrinsic values of the species. Then, the characteristics of the individuals are inserted, using information from the following variables: longevity, age of sexual maturity, tolerance value (ranging from tol $=1$ to 0 with 0.05 intervals) and random optimal values (random numbers). Optimal values will not influence the model, as they are irrelevant when $S=1$. This way, we created initial conditions to generate the first cohort with $\mathrm{n}=10,000$ individuals aged $=$ zero (year of age). Each individual is created based on the variation of the optimum and tolerance.

Submodels

Intrinsic birth ( $\mathrm{b} 0$ ) and mortality ( $\mathrm{d} 0$ ) rates. For one of our models, we had to define b0 and d0 of the estimated natural populations. b0 (Equation 1 ) and d0 (Equation 2) were calculated using the following expressions ${ }^{59}$.

$b=\frac{B}{N \cdot t}$ Equation 1

where B represents the number of births, and $N$.t represents the size of the current population.

$d=\frac{D}{N . t}$ Equation 2

Where, D represents the number of deaths, and N.t represents the size of the current population. We considered only the females (50\% of the value) of each population in the calculations.

Both b0 (0.6) and d0 (0.3) showed the same result in the three populations.

Aging of individuals and competition. Each cohort is aged by adding one year. Effective number $(\mathrm{Ne})$ is calculated by the product of the radius and the population size (sum of all living individuals in the base year).

Birth. From the third year of life, when the age of sexual maturity begins, individuals start reproduction and births are calculated by individuals, following equation $3^{59}$ :

$\mathrm{B}=\mathrm{b} 0+\mathrm{b} 1 *$ Ne Equation 3

Where, b0 represents the intrinsic birth rate, b1 when each individual interferes with population growth and Ne the effective number.

Mortality due to the number of individuals. Depending on the radius and population growth, individuals are removed from the population, following the following equation 4 :

$\mathrm{D}=\mathrm{d} 0+\mathrm{d} 1 * \mathrm{Ne}$ Equation 4

Where, $\mathrm{d} 0$ represents the intrinsic mortality rate, $\mathrm{d} 1 \mathrm{when}$ each individual interferes in the mortality of the population and Ne the effective number.

Mortality by age. When the surviving individuals of each cohort reach 12 years of age, they are eliminated from the population by the aging mortality process.

Delimitation of natural populations and viability study

As for the third objective, to infer about the viability status of natural populations, we defined the existence of three populations of $H$. zebra considering the proximity of the known occurrence points and possible natural barriers (Figure 2), since there are no studies that define the size of existing natural populations. Taking into account that we do not know the location of the geographical barriers that separate the populations, we defined only three natural populations: Gorgulho da Rita (from the city of Altamira to Volta Grande), Volta Grande (from the downstream of Altamira to the upstream of Vila Belo Monte) and Belo Monte (from Vila Belo Monte to Vitória do Xingu; Figure 2).

Population sizes were defined based on literature and informal reports by fishermen and personal observations. This informal estimate was supported by the rate of offered smuggled specimens on the internet. According to some information, in 2017, around 10,000 specimens of $H$. zebra were removed, from nature, monthly in the dry season (July to November). It was assumed that in the high-water period, 40\% (4,000 individuals / month) of this quantity was illegally collected. We assume that the number of individuals taken from nature represents $10 \%$ of the population, generating a total size of $7,800,000$ distributed among three populations. The abundance of each population was estimated based on the abundance of the capture samples of Gonçalves (2011). Given the total size of the species' metapopulation, we consider that $15 \%(1,170,000$ individuals) belong to Gorgulho da Rita, $60 \%(4,680,000)$ are in Volta Grande and $25 \%(1,950,000)$ in Belo Monte. So, the study of the viability of the three populations was carried out through the interface that combines birth with mortality rates, using the MetaZebra 01 algorithm. We used the values that can be found in equations 1 and 2 (see Submodels) of intrinsic birth rate (b0 = 0.6 ) and intrinsic mortality rate $(\mathrm{d} 0=0.3)$ for the three natural populations and related their viability status.

Page $8 / 13$ 


\section{Declarations}

\section{Author Contributions}

L.C.N.S. analyzed the data and results, wrote the main manuscript; L.M.S. contributed to the revision of the text; P.D.M.J. contributed to manuscript design and supervision and T.B.V. supervised the study and analyzed the data. All authors revised the text during the review process and gave approval before submission.

\section{Funding information}

Coordenação de Aperfeiçoamento de Pessoal de Nível Superior - Brasil (CAPES) - Finance Code 001.

\section{Ethical statements}

Not applicable

\section{Consent to participate}

Not applicable

\section{Consent to publish}

Not applicable

\section{Competing Interests}

The authors declare no competing interests.

\section{Additional Information}

Supplementary Information The online version contains supplementary material available at https://doi.org/10.5061/dryad.msbcc2g0h

Correspondence and requests for materials should be addressed to L.C.N.S.

\section{Acknowledgments}

This study was financed in part by the Coordenação de Aperfeiçoamento de Pessoal de Nível Superior - Brasil (CAPES) - Finance Code 001. We thank Rita Pelicano for revising the English.

\section{References}

1. Vörösmarty, C. J. et al. Global threats to human water security and river biodiversity. Nature 467, 555-561 (2010).

2. Arantes, C. C., Fitzgerald, D. B., Hoeinghaus, D. J. \& Winemiller, K. O. Impacts of hydroelectric dams on fishes and fisheries in tropical rivers through the lens of functional traits. Curr. Opin. Environ. Sustain. 37, 28-40 (2019).

3. Winemiller, K. O. et al. Balancing hydropower and biodiversity in the Amazon, Congo, and Mekong. Science (80-.). 351, 128-129 (2016).

4. Rivinoja, P., McKinnell, S. \& Lundqvist, H. Hindrances to upstream migration of atlantic salmon (Salmo salar) in a northern Swedish river caused by a hydroelectric power-station. Regul. Rivers Res. Manag. 17, 101-115 (2001).

5. Gao, X., Zeng, Y., Wang, J. \& Liu, H. Immediate impacts of the second impoundment on fish communities in the Three Gorges Reservoir. Environ. Biol. Fishes 87, 163-173 (2010).

6. Abernathy, A. R. \& Cumbie, P. M. Mercury accumulation by largemouth bass (Micropterus salmoides) in recently impounded reservoirs. Bull. Environ. Contam. Toxicol. 17, 595-602 (1977).

7. Zhong, Y. \& Power, G. Environmental impacts of hydroelectric projects on fish resources in China. Regul. Rivers Res. Manag. 12, 81-98 (1996).

8. Dudgeon, D. The Ecology of Tropical Asian Rivers and Streams in Relation to Biodiversity Conservation. Annu. Rev. Ecol. Syst. 31, 239-263 (2000).

9. Forsberg, B. R. et al. The potential impact of new Andean dams on Amazon fluvial ecosystems. (2017).

10. Barthem, R. B., de Brito Ribeiro, M. C. L. \& Petrere, M. Life strategies of some long-distance migratory catfish in relation to hydroelectric dams in the Amazon Basin. Biol. Conserv. 55, 339-345 (1991).

11. Araújo, E. S. et al. Changes in distance decay relationships after river regulation: similarity among fish assemblages in a large Amazonian river. Ecol. Freshw. Fish 22, 543-552 (2013).

12. Baxter, R. M. Environmental Effects of Dams and Impoundments. Annu. Rev. Ecol. Syst. 8, 255-283 (1977).

13. Cooney, P. B. \& Kwak, T. J. Spatial Extent and Dynamics of Dam Impacts on Tropical Island Freshwater Fish Assemblages. Bioscience 63, $176-190$ (2013).

14. Fearnside, P. M. Impacts of Brazil's Madeira River Dams: Unlearned lessons for hydroelectric development in Amazonia. Environ. Sci. Policy 38, 164-172 (2014). 
15. Agostinho, A. A., Pelicice, F. M. \& Gomes, L. C. Dams and the fish fauna of the Neotropical region: impacts and management related to diversity and fisheries. Brazilian J. Biol. 68, 1119-1132 (2008).

16. Xiao-Yang, Shao, Li Dao-Feng, and C. Q.-H. The composition of the fish community in Xiangxi Bay and resources evaluation. Acta Hydrobiol. Sin. 30, 7074 (2006).

17. Peňáz, M., Baruš, V. \& Prokeš, M. Changes in the structure of fish assemblages in a river used for energy production. Regul. Rivers Res. Manag. 15, 169180 (1999).

18. De Mérona, B. \& Albert, P. Ecological monitoring of fish assemblages downstream of a hydroelectric dam in French Guiana (South America). Regul. Rivers Res. Manag. 15, 339-351 (1999).

19. de Mérona, B., Vigouroux, R. \& Tejerina-Garro, F. L. Alteration of Fish Diversity Downstream from Petit-Saut Dam in French Guiana. Implication of Ecological Strategies of Fish Species. Hydrobiologia 551, 33-47 (2005).

20. Bunn, S. E. \& Arthington, A. H. Basic Principles and Ecological Consequences of Altered Flow Regimes for Aquatic Biodiversity. Environ. Manage. 30, 492507 (2002).

21. Clemento, A. J., Anderson, E. C., Boughton, D., Girman, D. \& Garza, J. C. Population genetic structure and ancestry of Oncorhynchus mykiss populations above and below dams in south-central California. Conserv. Genet. 10, 1321-1336 (2009).

22. Pelicice, F. M., Pompeu, P. S. \& Agostinho, A. A. Fish conservation must go beyond the concrete: A comment on Celestino et al. (2019). River Res. Appl. 36, 1373-1376 (2020).

23. Wilkes, M. A. et al. Not just a migration problem: Metapopulations, habitat shifts, and gene flow are also important for fishway science and management. River Res. Appl. 35, 1688-1696 (2019).

24. Lees, A. C., Peres, C. A., Fearnside, P. M., Schneider, M. \& Zuanon, J. A. S. Hydropower and the future of Amazonian biodiversity. Biodiversity and Conservation (2016). doi:10.1007/s10531-016-1072-3

25. Fearnside, P. M. Brazil's Belo Monte Dam: Lessons of an Amazonian resource struggle. 1-29 (2017).

26. Branquinho, A. \& Brito, D. Impact of dams on global biodiversity: A scientometric analysis. Neotrop. Biol. Conserv. 11, 101-109 (2016).

27. Pereira, H. R. et al. Research on dams and fishes: determinants, directions, and gaps in the world scientific production. Hydrobiologia $847,579-592$ (2020).

28. Graham, E. B., Stegen, J. C., Huang, M., Chen, X. \& Scheibe, T. D. Subsurface biogeochemistry is a missing link between ecology and hydrology in damimpacted river corridors. Sci. Total Environ. 657, 435-445 (2019).

29. Tuberville, T. D. et al. Using Demographic Sensitivity Testing to Guide Management of Gopher Tortoises at Fort Stewart, Georgia: A Comparison of Individual-Based Modeling and Population Viability Analysis Approaches. in Ecologist-Developed Spatially-Explicit Dynamic Landscape Models (eds. J., W. \& G., C.) 109-131 (Springer US, 2012). doi:10.1007/978-1-4614-1257-1_7

30. Giacomini, H. C. Sete motivações teóricas para o uso da modelagem baseada no indivíduo em ecologia. 37, (2007).

31. Jorgensen, S. E. Fundamentals of Ecological Modelling. (Elsevier Science Ltd, 2011).

32. DeAngelis, D. L., Rose, K. A. \& Huston, M. A. Individual-Oriented Approaches to Modeling Ecological Populations and Communities. in Frontiers in Mathematical Biology (ed. Levin, S. A.) 390-410 (Springer, 1994). doi:10.1007/978-3-642-50124-1_24

33. Boyce, M. S. Population Viability. Annu. Rev. Ecol. Syst. 23, 481-506 (1992).

34. Giacomini, H. C. A Vulnerabilidade da Ictiofauna à Invasão por Espéciesde Peixes: Um Modelo Baseado no Individuo. (Universidade Estadual Paulista, 2006).

35. Shin, Y.-J. \& Cury, P. Exploring fish community dynamics through size-dependent trophic interactions using a spatialized individual-based model. Aquat. Living Resour. 14, 65-80 (2001).

36. Van Nes, E. H., Lammens, E. H. R. R. \& Scheffer, M. PISCATOR, an individual-based model to analyze the dynamics of lake fish communities. Ecol. Modell. 152, 261-278 (2002).

37. Vari, R. P. \& Malabarba, L. R. Neotropical Ichthyology: An Overview. Phylogeny Classif. Neotrop. Fishes 1, 1-12 (1998).

38. Petrere, M. Fisheries in large tropical reservoirs in South America. Lakes Reserv. Res. Manag. 2, 111-133 (1996).

39. Fearnside, P. M. Avança Brasil: Environmental and Social Consequences of Brazil's Planned Infrastructure in Amazonia. Environ. Manage. 30, 735-747 (2002).

40. Toussaint, A., Charpin, N., Brosse, S. \& Villéger, S. Global functional diversity of freshwater fish is concentrated in the Neotropics while functional vulnerability is widespread. Sci. Rep. 6, 22125 (2016).

41. Pérez, M. S. Where the Xingu Bends and Will Soon Break. Am. Sci. 103, 395-403 (2015).

42. Fitzgerald, D. B. et al. Diversity and community structure of rapids-dwelling fishes of the Xingu River: Implications for conservation amid large-scale hydroelectric development. Biol. Conserv. (2018). doi:10.1016/j.biocon.2018.04.002

43. Camargo, M., Giarrizzo, T. \& Isaac, V. J. Review of the geographic distribution of fish fauna of the Xingu River Basin, Brazil. Ecotropia 10, 123-147 (2004).

44. Akama, A. et al. Hypancistrus zebra Isbrücker \& Nijssen, 1991. in Livro Vermelho da Fauna Brasileira Ameaçada de Extinção: Peixes (ed. ICMBio/MMA) vi, 346-348 (2018).

45. Camargo, M., Gimenes-Junior, H., Sousa, L. M. de \& Py-Daniel, L. R. Loricariids of the Middle Rio Xingu. Loricariiden des mittleren Rio Xingu. Hanover Matthias Kählig, Panta Rhei GmbH 2, (2013). 
46. Fricke, R., Eschmeyer, W. N. \& Fong, J. D. Species by Family/ Subfamily. Eschmeryer's Catalog of Fishes (2019). Available at: http://researcharchive.calacademy.org/research/ichthyology/catalog/collections.asp. (Accessed: 25th February 2019)

47. Isbrucker, I. J. H. \& Nijssen, H. Hypancistrus zebra, a new genus and species of ancistrine loricariid fish from the Rio Xingu, Brazil (Pisces: Siluriformes: Loricariidae). Ichthyol. Explor. Freshwaters 1, 345-350 (1991).

48. Pereira, D. A. S. \& Henriques, M. B. Economic feasibility for producing Imperial Zebra pleco (Hypancistrus zebra) in recirculating aquaculture systems: An alternative for a critically endangered ornamental fish. Aquac. Econ. Manag. 23, 428-448 (2019).

49. Sousa, L. M., Lucanus, O., Arroyo-Mora, J. P., \& Kalacska, M. Conservation and trade of the endangered Hypancistrus zebra (Siluriformes, Loricariidae), one of the most trafficked Brazilian fish. Global Ecology and Conservation, 27, e01570 (2021).

50. The MathWorks, Inc., 2015. MATLAB® R2015a. (2015).

51. Borghezan, R. Ecologia populacional e comportamento de peixes subterrâneos, Rhamdia sp. n. e Ancistrus sp. n., da área cárstica da Serra da Bodoquena, Mato Grosso do Sul (Siluriformes: Heptapteridae, Loricariidae). (Universidade de São Paulo, 2013). doi:10.11606/D.41.2013.tde-12062013090146

52. Secutti, S. \& Trajano, E. Reproductive behavior, development and eye regression in the cave armored catfish, Ancistrus cryptophthalmus Reis, 1987 (Siluriformes: Loricariidae), breed in laboratory. Neotrop. Ichthyol. 7, 479-490 (2009).

53. Trajano, E. \& Bichuette, M. E. Population ecology of cave armoured catfish, Ancistrus cryptophthalmus Reis 1987, from central Brazil (Siluriformes: Loricariidae). Ecol. Freshw. Fish 16, 105-115 (2007).

54. Duncan, I. J. H. \& Fraser, D. Understanding animal welfare. in Animal Welfare (eds. Appleby, M. \& Hughes, B. O.) 19-37 (GABI Publishing, 1997).

55. Ramos, F. M. Peixes ornamentais do rio Xingu: Manutenção e reprodução do acari zebra Hypancistrus zebra ISBRÜCKER \& NIJSSEN, 1991 (Siluriformes, Loricariidae) em cativeiro. (Universidade Federal do Pará, 2016).

56. Gonçalves, A. P. Ecologia e etnoecologia de Hypancistrus zebra (Siluriformes: Loricariidae) no rio Xingu, Amazônia brasileira. (Universidade Federal do Pará, 2011).

57. Roman, A. P. O. Biologia reprodutiva e dinâmica populacional de Hypancistrus zebra Isbrücker \& Nijssen, 1991 (Siluriformes, loricariidae) no rio Xingu, amazônia brasileira. Universidade Federal Do Pará 22, (Universidade Federal do Pará, 2011).

58. Zuanon, J. A. S., Salaro, A. L. \& Furuya, W. M. Production and nutrition of ornamental fish. Rev. Bras. Zootec. 40, 165-174 (2011).

59. Gotelli, N. J. Ecologia. (Editora Planta, 2007).

60. Groner, E., Begon, M., Harper, J. L. \& Townsend, C. R. Ecology; Individuals, Populations and Communities. J. Anim. Ecol. (2006). doi:10.2307/6030

61. Pulliam, H. R. On the relationship between niche and distribution. Ecology Letters (2000). doi:10.1046/j.1461-0248.2000.00143.x

62. Hirzel, A. H. \& Le Lay, G. Habitat suitability modelling and niche theory. Journal of Applied Ecology (2008). doi:10.1111/j.1365-2664.2008.01524.x

63. Vandermeer, J. H. Niche Theory. Annu. Rev. Ecol. Syst. (2003). doi:10.1146/annurev.es.03.110172.000543

64. Chapman, E. J. \& Byron, C. J. The fl exible application of carrying capacity in ecology. 13, 1-12 (2018).

65. Price, D. Carrying capacity reconsidered. Popul. Environ. 21, 5-26 (1999).

66. Parry, G. D. The Meanings of r- and K-Selection. Oecologia 48, 260-264 (1981).

67. Roughgarden, J. Density-dependent Natural Selection. Ecol. Soc. Am. 52, 453-468 (1971).

68. Boitani, L. \& Todd, F. Research techniques in animal ecology: controversies and consequences. (Columbia University Press, 2000).

69. Dennis, B., Munholland, P. L. \& Scott, J. M. Estimation of Growth and Extinction Parameters for Endangered Species. Ecol. Monogr. 61, 115-143 (1991).

70. Ruggiero, L. F., Hayward, G. D. \& Squires, J. R. Viability Analysis in Biological Evaluations: Concepts of Population Viability Analysis, Biological Population, and Ecological Scale. Conserv. Biol. 8, 364-372 (1994).

71. Groom, M. J. \& Pascual, M. A. The Analysis of Population Persistence: An Outlook on the Practice of Viability Analysis. in Conservation Biology (1998). doi:10.1007/978-1-4757-2880-4_1

72. Lande, R. Risks of population extinction from demographic and environmental stochasticity and random catastrophes. Am. Nat. 142, (1993).

73. Pimm, S. L. \& Redfearn, A. The variability of animal populations. Nature 334, (1988).

74. Hackney, E. E. \& McGraw, J. B. Experimental Demonstration of an Allee Effect in American Ginseng. Conserv. Biol. 15, 129-136 (2001).

75. Gimenez, O., Cam, E. \& Gaillard, J.-M. Individual heterogeneity and capture-recapture models: what, why and how? Oikos 127, 664-686 (2017).

76. Lacy, R. C. Vortex: A stochastic simulation of the extinction process. Version 10.3.8. (Chicago Zoological Society, 2020).

77. Pe'Er, G. et al. A protocol for better design, application, and communication of population viability analyses. Conserv. Biol. 27, (2013).

78. Ludwig, D. Is it meaningful to estimate a probability of extinction? Ecology 80, 298-310 (1999).

79. Soulé, M. E. Viable populations for conservation. (Cambridge University Press, 1987).

80. Huse, G. Individual-based Modeling and Ecology. Fish Fish. 9, 215-216 (2008).

81. Grimm, V. Individual-based models. In: Jørgensen, S.E., Fath, B.D. (Eds.),,, vols. 5. Elsevier, Oxford, pp. in Ecological Models, Vol. [3] of Encyclopedia of Ecology, vols. 5 (eds. Jørgensen, S. E. \& Fath, B. D.) 1959-1968 (Elsevier, 2008).

82. DeAngelis, D. L. \& Mooij, W. M. Individual-Based Modeling of Ecological and Evolutionary Processes. Annu. Rev. Ecol. Evol. Syst. 36, 147-168 (2005).

83. Newton, I. Lifetime reproduction in birds. Lifetime Reprod. birds (1989). doi:10.2307/5045

84. Douhard, M. et al. Fitness consequences of environmental conditions at different life stages in a long-lived vertebrate. Proc. R. Soc. B Biol. Sci. 281, (2014). 
85. Berger, V., Lemaître, J. F., Allainé, D., Gaillard, J. M. \& Cohas, A. Early and adult social environments have independent effects on individual fitness in a social vertebrate. Proc. R. Soc. B Biol. Sci. 282, (2015).

86. Cody, M. L. A General Theory of Clutch Size. Evolution (N. Y). 20, 174-184 (1966).

87. Radchuk, V., Ims, R. A. \& Andreassen, H. P. From individuals to population cycles: the role of extrinsic and intrinsic factors in rodent populations. Ecology 97, 720-732 (2016).

88. Zuanon, J. \& Rapp Py-Daniel, L. H. Hypancistrus zebra. P. 220. in Livro Vermelho da Fauna Brasileira Ameaçada de Extinção (eds. Machado, A. B. M., Drummond, G. M. \& Paglia, A. P.) 907 (Ministério do Meio Ambiente e Fundação Biodiversitas, 2008).

89. IBAMA. Diagnóstico Geral das Práticas de Controle Ligadas a Exploração, Captura, Comercialização, Exportação e Uso de Peixes para Fins Ornamentais e de Aquariofilia. 217 (2008).

90. Frederico, R. G., Olden, J. D. \& Zuanon, J. Climate change sensitivity of threatened, and largely unprotected, Amazonian fishes. Aquat. Conserv. Mar. Freshw. Ecosyst. 26, 91-102 (2016).

\section{Figures}

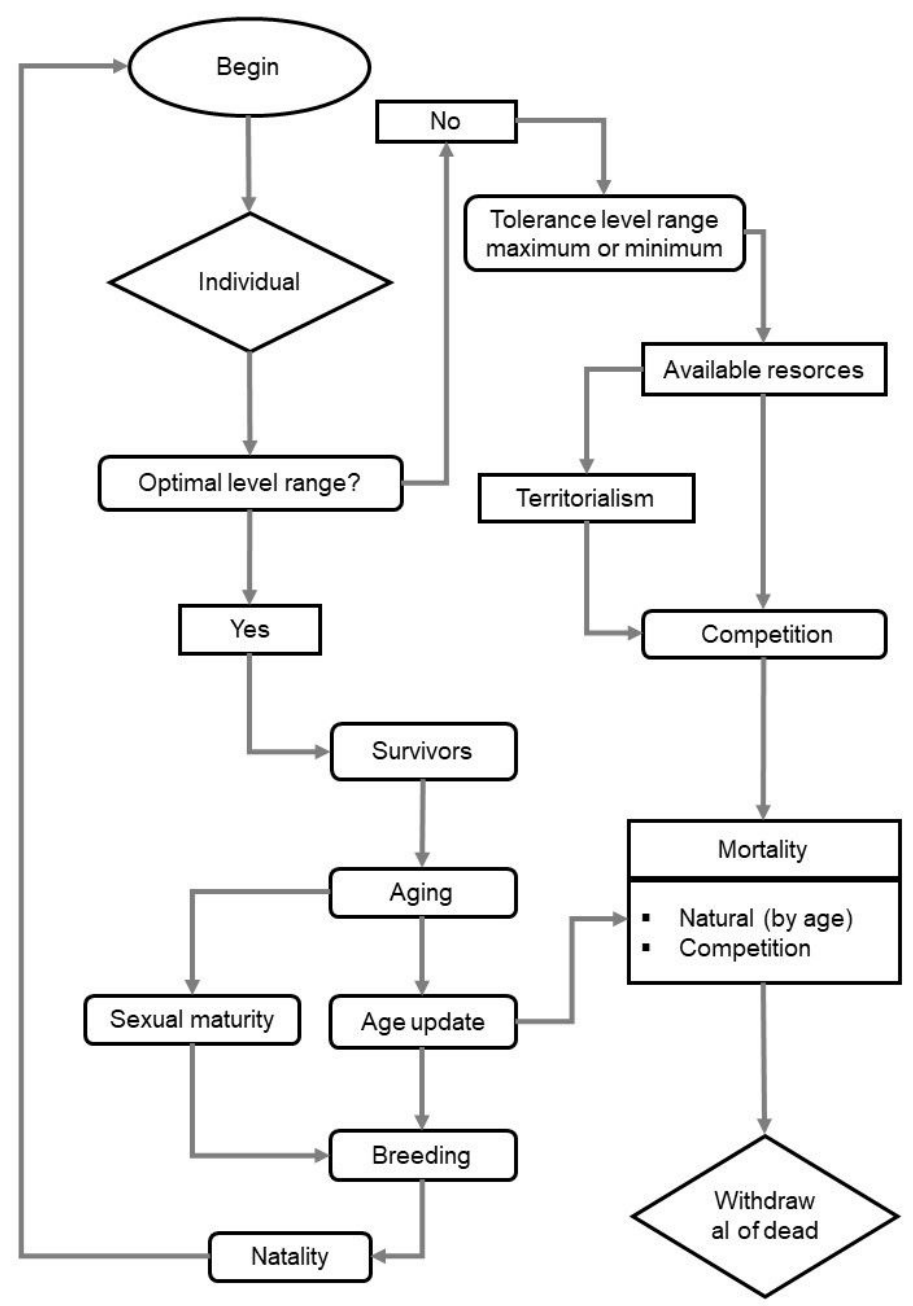

Figure 1

Processes that promote the dynamics of specimens in the model over an interval of 1,000 years. 


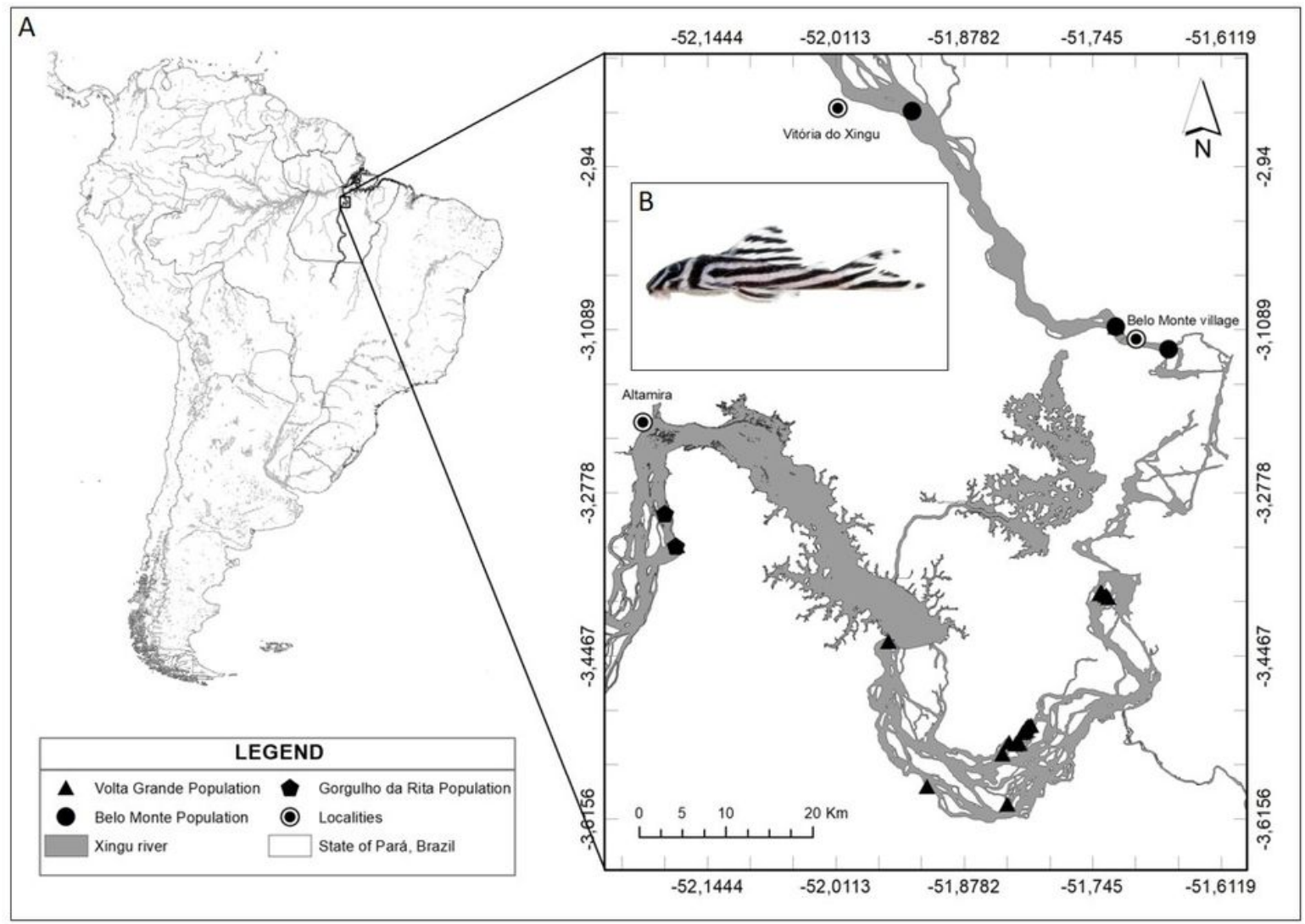

\section{Figure 2}

Species occurrence area in the current overlap of the stretch: (A) Distribution of the occurrence points of the three hypothetical populations: Gorgulho da Rita, Volta Grande and Belo Monte; (B) Illustrative image of Hypancistrus zebra.

\section{Supplementary Files}

This is a list of supplementary files associated with this preprint. Click to download.

- SupplementaryIPopZebra.txt

- SupplementaryllMetaZebra01.txt

- SupplementaryIIIMetaZebra02.txt 